\title{
Management of Paclitaxel-Induced Hand-Foot Syndrome
}

\author{
Hussein A. Assi Zeina A. Ayoub Sara M. Jaber Hassan A. Sibai Nagi S. El Saghir
}

Department of Internal Medicine, American University of Beirut Medical Center, Beirut, Lebanon

\section{Keywords}

Hand-foot syndrome · Paclitaxel · Breast cancer

\section{Summary}

Background: Hand-foot syndrome (HFS), also known as acral erythema or palmoplantar dysesthesia, is a manifestation of painful erythema and dysesthesia mostly occurring in the palms and soles. Although many chemotherapeutic agents have been shown to cause HFS, it remains an uncommon adverse cutaneous manifestation of paclitaxel. Case Report: We report a case of paclitaxel-induced grade $3 \mathrm{HFS}$ in a patient with breast cancer. HFS developed after 6 weeks of paclitaxel weekly infusions. The patient was managed by avoidance of sun exposure and extensive use of sunscreen and moisturizers. The skin lesions stabilized and improved gradually. This allowed us to continue the planned necessary course of 12 weeks of paclitaxel under close surveillance. Conclusion: Paclitaxel-induced HFS can be managed with topical creams and avoidance of sun exposure without the need to discontinue chemotherapy. However, close monitoring for any increase or change in symptoms is warranted.

\section{Introduction}

Hand-foot syndrome (HFS), also known as acral erythema or palmoplantar dysesthesia, is a manifestation of painful erythema and dysesthesia mostly occurring in the palms and soles. Patients usually present with a spectrum of symptoms which range from burning, tingling, and skin erythema in the extremities in mild cases to pain, edema, and ulcerations in more severe cases. HFS was first shown to be associated with mitotane by Zuehlke in 1974 [1]; since then, many

\author{
Schlüsselwörter \\ Hand-Fuß-Syndrom · Paclitaxel · Mammakarzinom
}

\section{Zusammenfassung}

Hintergrund: Hand-Fuß-Syndrom (HFS), auch bekannt als akrales Erythem oder palmoplantare Erythrodysästhesie, manifestiert sich als schmerzhaftes Erythem und Dysästhesie vorrangig im Bereich der Handflächen und Fußsohlen. Viele Chemotherapeutika können HFS auslösen, im Fall von Paclitaxel ist es jedoch eine seltene kutane Nebenwirkung. Fallbericht: Wir berichten von einem Fall von durch Paclitaxel induziertem Grad-3-HFS bei einer Patientin mit Mammakarzinom. Das HFS manifestierte sich nach 6 wöchentlichen Paclitaxel-Infusionen. Management bestand aus Vermeidung von direktem Sonnenlicht und ausgiebiger Anwendung von Sonnenschutz- und Feuchtigkeitscremes. Die Hautläsionen stabilisierten und verbesserten sich nach und nach, wodurch die geplante 12-wöchige Paclitaxel-Therapie unter Beobachtung fortgesetzt werden konnte. Schlussfolgerung: Durch Paclitaxel induziertes HFS kann mit topischen Cremes und Vermeidung von direkter Sonnenbestrahlung unter Kontrolle gebracht werden, ohne dass die Chemotherapie abgebrochen werden muss. Jedoch bedarf es einer strengen Überwachung für den Fall, dass es zu einer erneuten Verschlechterung der Symptome kommt.

chemotherapeutic agents have been shown to cause this dermatological pathology [1]. Taxanes are a group of chemotherapeutic agents that act as mitotic inhibitors. They bind to tubulin and cause hyperstabilization of the microtubules, prevent them from depolymerizing, and ultimately lead to an arrest of mitosis. Through this mechanism, taxanes have shown significant activity against breast, lung, ovarian, and head and neck cancers. Like many other antineoplastic drugs, they have various toxicities that include myelosupression, neuropathies, and mucocutaneous manifestations [2]. Although docetaxel,

\section{KARGER}

Fax +497614520714

Information@Karger.com

www.karger.com (c) 2013 S. Karger GmbH, Freiburg

$1661-3791 / 13 / 0083-0215 \$ 38.00 / 0$

Accessible online at:

www.karger.com/brc
Nagi S. El Saghir, MD, FACP

Professor of Clinical Medicine/Hematology-Oncology

Director, Breast Center of Excellence, NK Basile Cancer Institute

American University of Beirut Medical Center

P.O. Box: 11-0236, Riad El Solh 1107 2020, Beirut, Lebanon

nagi.saghir@aub.edu.lb 
a widely used taxane chemotherapeutic agent, has been linked to palmoplantar dysesthesia in clinical trials, clinical practice, and many case reports [3-5], such an association has not been as frequently established with paclitaxel, except in 3 reported cases and in 1 prospective study [2, 3, 6, 7]. When HFS is diagnosed, physicians usually discontinue the offending agent, and the syndrome starts to resolve slowly, with residual skin pigmentation in some cases [2,8-11]. However, in cases of adjuvant therapy of early breast cancer, the use of taxanes may be considered essential, as many studies have shown that it improves survival, and the continuation of the drug is desirable. It is in this context that we present a case of paclitaxelinduced HFS in a patient with high-risk early breast cancer. We describe our case of HFS and the approach to its management in order to complete the full course of paclitaxel.

\section{Case Report}

A 72-year-old woman, known to have diabetes mellitus type 2, dyslipidemia and hypertension, was diagnosed to have infiltrating ductal carcinoma of the right breast in June 2011, stage T1 $(1.5 \mathrm{~cm}) \mathrm{N} 3(18 / 26$ lymph nodes) M0, estrogen receptor-positive, progesterone receptor-positive, HER2/neu-negative. After partial mastectomy and axillary lymph node dissection, she was started on adjuvant chemotherapy with weekly paclitaxel $\left(80 \mathrm{mg} / \mathrm{m}^{2}\right.$ intravenous (IV) infusion over $1 \mathrm{~h}$ ), planned for 12 weeks, to be followed by 4 cycles of CEF (cyclophosphamide, epirubicin, 5 -fluorouracil). She was premedicated with $8 \mathrm{mg}$ dexamethasone, $3 \mathrm{mg}$ granisetron, $50 \mathrm{mg}$ diphenhydramine, and $100 \mathrm{mg}$ ranitidine, all administered IV prior to each weekly session. After the 6th weekly dose of paclitaxel, the patient started to develop macular erythema over the maxillary area, neck, hands, and feet, associated with swelling and dysesthesia. The patient suffered from a tingling sensation, particularly over the tips of the fingers and toes, preventing her from pursuing activities of daily living. Her nails started to become fragile. The onset of symptoms was insidious, but the patient kept progressing over the following 2 weeks, both in intensity and extent of involvement with ulceration and blistering (fig. 1). The erythema extended over the whole upper extremities, upper chest, as well as the lower extremities up to the level of the knees. She had neither fever nor any systemic symptoms. On physical examination, the rash was erythematous, macular, very well demarcated, and associated with desquamation and edema. The lesions were prominent at sun-exposed areas of the skin (neck, cheeks, and chin). Her nails were brittle and started to detach from the nail bed. The patient was therefore diagnosed to have grade 3 HFS, according to the World Health Organization (WHO) criteria. She was instructed to wear long sleeves and cover up the sun-exposed areas of the face and neck, and to generously apply sunscreen and moisturizing creams. After 1 week, the patient improved, and we continued her chemotherapeutic treatment as planned. The skin symptoms stabilized and transiently decreased in size (fig. 2). Therefore, we continued weekly paclitaxel with close observation along with continued topical applications. The lesions did not progress to a more advanced stage of disease. After the 12th dose of paclitaxel, the patient started to show more gradual improvement, and within 2 weeks the extent of the lesions had markedly decreased; she had no more dysesthesia, and the rash turned into dark brown patches. Skin peeling was prominent and decreased slowly during recovery. After paclitaxel, the patient was given 4 cycles of 3-weekly CEF. No recurrence of HFS was noted, even though she reported transient discomfort of 2 days duration following each cycle of CEF. After 2 months, there was only residual mild skin pigmentation on the feet (fig. 3) and sun-exposed areas (fig. 4).

\section{Discussion}

Paclitaxel has been known to be associated with a wide spectrum of adverse cutaneous reactions since its first use as a chemotherapeutic agent in 1957 [8]. Examples of such events include mucositis, onycholysis, radiation recall dermatitis, erythema multiforme, pustular eruptions, and scleroderma-like changes $[6,9]$. One uncommon cutaneous manifestation of paclitaxel is HFS of which only 5 cases have been reported in the literature. The first case report was described in 1996 by Di Argila et al. [3]; the patient received 310-400 mg of IV paclitaxel every 3 weeks for treatment of breast cancer. She developed grade 2 acral erythema after the 4th dose. Paclitaxel was continued until the 10th cycle after which it was discontinued due to brain metastasis. Another breast cancer patient known to have hepatic dysfunction was also reported in 1996 by Payne et al. [2]; she was given a bolus dose of $135 \mathrm{mg}$ paclitaxel IV over $24 \mathrm{~h}$, and grade 4 symptoms of HFS were reported on day 8 post-infusion. This severe reaction was attributed to the patient's known hypoalbuminemia; since most of the circulating paclitaxel is bound to proteins, a low albumin level might have contributed to this severe adverse reaction. The patient refused further chemotherapy. The 3rd

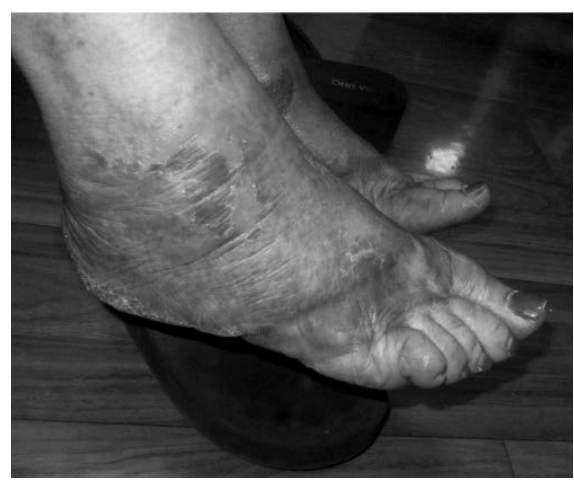

Fig. 1. Early stage of hand-foot syndrome with prominent desquamation, ulceration, and blistering of the feet.

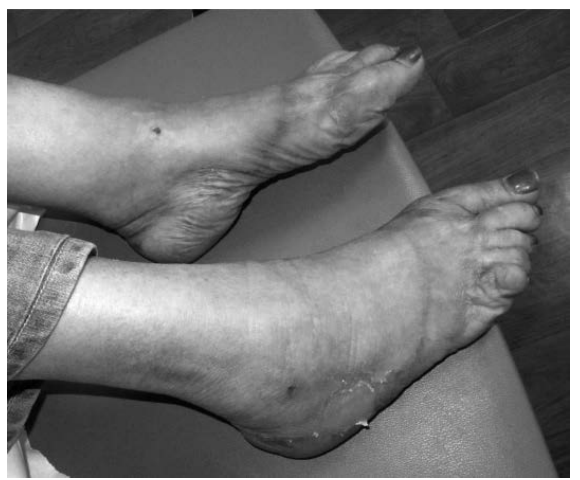

Fig. 2. Late stage of hand-foot syndrome with residual skin peeling and mild erythema.

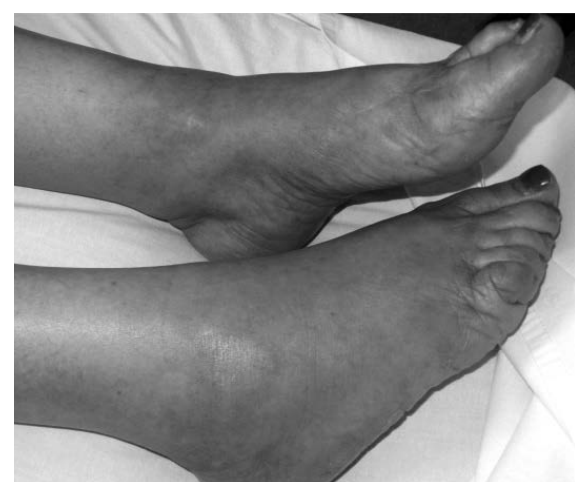

Fig. 3. Resolution of lesions with residual pigmentation on the dorsum of the feet and ankles. 


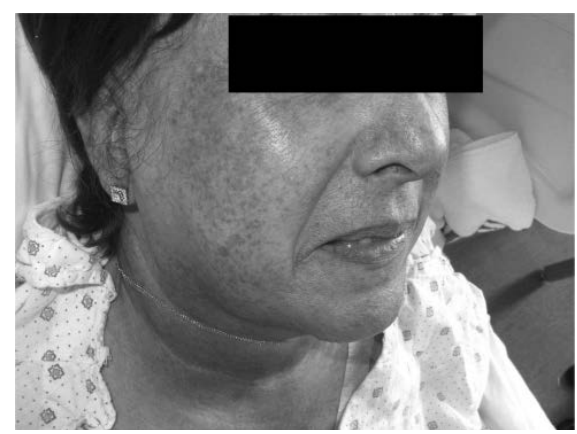

Fig. 4. Resolution of hand-foot syndrome in sun-exposed areas of the face and neck with mild residual pigmentation on her cheeks.

case report of acral erythema associated with paclitaxel was reported by Cruz et al. in 2010 [6]. The symptoms started after the 2nd week of drug administration, after which paclitaxel was discontinued.

In a prospective follow-up of 2,186 patients who received different chemotherapy regimens in Valencia, Spain, 44 patients were reported to have developed chemotherapyinduced acral erythema. Of the 127 patients who received paclitaxel, only 2 patients developed grade 2 HFS [7]. This corresponds to an occurrence rate of $1.5 \%$. This rate is lower compared to that of docetaxel where 6 out of 156 patients (equivalent to $3.2 \%$ ) developed HFS. Moreover, the docetaxel-induced HFS cases ranged in severity between grade 2 and grade 3, making it more severe than paclitaxel-induced HFS.

In the literature, most reported cases showed that HFS usually occurred 2 weeks into the treatment $[4,5,10]$. This is in contrast to our patient who developed her symptoms after the 6 th weekly dose $\left(80 \mathrm{mg} / \mathrm{m}^{2}\right)$ of paclitaxel. Paclitaxelinduced HFS could be dependent on cumulative doses of the drug, as reported with other chemotherapeutic agents [5, 7].

Concerning the management of chemotherapy-induced HFS, discontinuation of the drug, or dose modification, are the only recommendations available [5]. Some measures that have been suggested to alleviate HFS symptoms include cold compresses, application of emollients, and avoidance of mechanical stress on the affected areas. Topical corticosteroids or dimethylsulfoxide have been used, but with no definitive results [11]. Oral or topical pyridoxine (vitamin B6) has been successful in some instances [12].

There are reported cases where the offending drug was replaced by another similar chemotherapeutic agent, which led to resolution of symptoms [4]. For example, docetaxel, which is known to cause HFS in about 6-37\% [10], can be switched to paclitaxel with favorable outcome [4]. This was not an option in our patient who was already started on paclitaxel. It was our opinion that paclitaxel is an essential medication that has been shown to improve survival in such a patient who is at high risk for breast cancer recurrence [13]. Therefore we continued paclitaxel and gave instructions to avoid sunlight and apply sunscreen and moisturizing creams aggressively. No further deterioration was noted.

\section{Conclusion}

We report a case of paclitaxel-induced grade 3 HFS in a patient with breast cancer. HFS developed after 6 weeks of paclitaxel weekly infusions. The patient was managed by avoidance of sun exposure and aggressive use of sunscreen and moisturizing creams. The skin lesions stabilized and improved gradually. This allowed us to continue the planned necessary course of 12 weeks of paclitaxel under close surveillance.

\section{Disclosure Statement}

There is no sponsorship or funding related to this case report. None of the authors of this manuscript declare any conflict of interest.

\section{References}

1 Susser WS, Whitaker-Worth DL, Grant-Kels JM: Mucocutaneous reactions to chemotherapy. J Am Acad Dermatol 1999;40:367-98.

2 Payne JY, Holmes F, Cohen PR, Gagel R, Buzdar A, Dhingra K: Paclitaxel: severe mucocutaneous toxicity in a patient with hyperbilirubinemia. South Med J 1996;89:542-5.

$\checkmark 3$ De Arila D, Dominguez JD, Iglesias L: Taxolinduced acral erythema. Dermatology 1996; 192:377-8.

4 Farhat MH, El-Saghir NS, Shamseddine AI: Handfoot syndrome with docetaxel: a five-case series. Ann Saudi Med 2008;28:374-7.

$\checkmark 5$ Nagore E, Insa A, Sanmartín O: Antineoplastic therapy-induced palmar plantar erythrodysesthesia ('hand-foot') syndrome: incidence, recognition and management. Am J Clin Dermatol 2000;1:225-34.

6 Cruz A, Temu T, Hines-Telang G, Kroumpouzos G: Paclitaxel-induced neutrophilic adverse reaction and acral erythema. Acta Derm Venereol 2011; 91:86-7.
7 Hueso L, Sanmartín O, Nagore E, BotellaEstrada R, Requena C, Llombart B, SerraGuillén C, Alfaro-Rubio A, Guillén C: Chemotherapy-induced acral erythema: a clinical and histopathologic study of 44 cases. Actas Dermosifiliogr 2008;99:281-90.

8 Rowinsky EK, Cazenave LA, Donehower RC: Taxol: a novel investigational antimicrotubule agent. J Natl Cancer Inst 1990;82:1247-59.

$\checkmark 9$ Cohen PR: Photodistributed erythema multiforme: paclitaxel-related, photosensitive conditions in patients with cancer. J Drugs Dermatol 2009;8:61-4.

10 Degen A, Alter M, Schenck F, Satzger I, Völker B, Kapp A, Gutzmer R: The hand-foot-syndrome associated with medical tumor therapy - classification and management. J Dtsch Dermatol Ges 2010;8:652-61.

11 Webster-Gandy JD, How C, Harrold K: Palmarplantar erythrodysesthesia (PPE): a literature review with commentary on experience in a cancer centre. Eur J Oncol Nurs 2007;11:238-46.
12 Farr KP, Safwat A: Palmar-plantar erythrodysesthesia associated with chemotherapy and its treatment. Case Rep Oncol 2011;4:229-35.

13 Martín M, Rodríguez-Lescure A, Ruiz A, Alba E, Calvo L, Ruiz-Borrego M, Munárriz B, Rodríguez CA, Crespo C, de Alava E, López García-Asenjo JA, Guitián MD, Almenar S, González-Palacios JF, Vera F, Palacios J, Ramos M, Gracia Marco JM, Lluch A, Alvarez I, Seguí MA, Mayordomo JI, Antón A, Baena JM, Plazaola A, Modolell A, Pelegrí A, Mel JR, Aranda E, Adrover E, Alvarez JV, García Puche JL, Sánchez-Rovira P, Gonzalez S, LópezVega JM: Randomized phase 3 trial of fluorouracil, epirubicin, and cyclophosphamide alone or followed by paclitaxel for early breast cancer. J Natl Cancer Inst 2008;100:805-14. 